\title{
CBResearch Square \\ Outcome of SARS-COV-2-Related Thyrotoxicosis in Survivors of COVID-19: A Prospective Study
}

\author{
Alessandro Pizzocaro \\ Humanitas Clinical and Research Center IRCCS \\ Paolo Colombo \\ Humanitas Clinical and Research Center IRCCS \\ Walter Vena \\ Humanitas Clinical and Research Center IRCCS \\ Salvatore Ariano \\ Humanitas Clinical and Research Center IRCCS \\ Paola Magnoni \\ Humanitas Clinical and Research Center IRCCS \\ Francesco Reggiani \\ Humanitas Clinical and Research Center IRCCS \\ Giuseppe Favacchio \\ Humanitas Clinical and Research Center IRCCS \\ Marco Mirani \\ Humanitas Clinical and Research Center IRCCS \\ Elisabetta Lavezzi \\ Humanitas Clinical and Research Center IRCCS \\ Marta Calatroni \\ Humanitas Clinical and Research Center IRCCS \\ Antonio Voza \\ Humanitas Clinical and Research Center IRCCS \\ Gherardo Mazziotti ( $\square$ Gherardo.mazziotti@hunimed.eu ) \\ Humanitas University https://orcid.org/0000-0001-5458-701X \\ Andrea Lania \\ Humanitas University
}

\section{Research Article}

Keywords: Covid-19, SARS-CoV2, thyroid, thyrotoxicosis, hyperthyroidism, TSH, thyroid hormones, thyroiditis

Posted Date: March 15th, 2021

DOI: https://doi.org/10.21203/rs.3.rs-287872/v1

License: (c) (i) This work is licensed under a Creative Commons Attribution 4.0 International License. Read Full License 


\section{Abstract}

\section{Purpose}

To evaluate the post- coronavirus disease-19 (COVID-19) outcome of thyroid function in patients with severe acute respiratory syndrome coronavirus 2 (SARS-CoV-2)-related thyrotoxicosis.

Methods

This was a single-center prospective study involving 29 patients ( 11 females, 18 males; median age 64 years, range: 43-85) with thyrotoxicosis diagnosed after hospitalization for COVID-19 and then followed-up for a median period of 90 days (range: 30-120) after hospital discharge. At the follow-up, patients were evaluated for serum thyrotropic (TSH), free-thyroxine (FT4), freetriiodiothyronine (FT3), TSH receptor antibodies (TRAb), thyroglobulin antibodies (TgAb), thyroperoxidase antibodies (TPOAb) and ultrasonographic thyroid structure.

Results

After recovery of COVID-19, serum TSH values significantly increased $(P<0.001)$ and FT4 values significantly decreased $(P=0.001)$, without significant change in serum FT3 $(P=0.572)$. At the follow-up, 28 subjects $(96.6 \%)$ became euthyroid whereas overt hypothyroidism developed in one case. At the ultrasound evaluation of thyroid gland, hypoecogenicity was found in 10 patients (34.5\%) with a prevalence that was significantly higher in cases with serum TSH $>3.0 \mathrm{mU} / \mathrm{l}$ as compared to those with TSH values below $1.0 \mathrm{mU} / \mathrm{L}(P=0.039)$. All subjects resulted to be negative for TgAb, TPOAb and TRAb.

Conclusion

In a short-term follow-up, thyroid function spontaneously normalized in most subjects with SARS-CoV-2-related thyrotoxicosis. However, thyroid hypoecogenicity was found in a remarkable number of them and future longer-term studies are needed to clarify whether this ultrasonographic alteration may predispose to develop late-onset thyroid dysfunction.

\section{Introduction}

The coronavirus disease-19 (COVID-19) pandemic caused by the severe acute respiratory syndrome coronavirus 2 (SARS-CoV-2) continues to affect the global community and in our country more than 2 million of individuals have been infected by SARS-CoV-2.

Although the pulmonary system is the main target of SARS-CoV2 infection [1], extrapulmonary organs can be affected with potential negative impact on clinical outcome of COVID-19 [2]. Interestingly, alterations of thyroid hormones resembling a subacute thyroiditis (SAT) have been consistently reported in a substantial number of subjects with COVID-19 [3-11], prompting to hypothesize that thyroid gland may be a frequent target of SARS-CoV2 infection [12,13]. However, the clinical relevance of thyrotoxicosis associated with SARS-CoV2 infection is still controversial $[3,14,15,4]$ and data on the outcome of thyroid function after remission of COVID-19 are scanty [14]. Specifically, it is still unknown whether thyroid gland may be persistently damaged by SARS-CoV2, such as demonstrated for other tissues and organs in individuals with COVID-19 [16].

In this prospective study, we aimed at evaluating the outcome of thyroid function and ultrasonographic structure after recovery of COVID-19 in individuals who had developed thyrotoxicosis during hospital stay for SARS-CoV2 infection.

\section{Materials And Methods}

This is a prospective single-center study performed on consecutive patients who had been hospitalized for COVID-19 at the IRCCS, Humanitas Research Hospital, Rozzano-Milan, Italy in the period between March $1^{\text {st }}$ and April $1^{\text {st }} 2020$ [3]. The inclusion criteria were: 1) hospitalization for COVID-19 diagnosed by real-time reverse-transcriptase-polymerase-chain-reaction assay of nasal and pharyngeal swab specimens and/or bronco-alveolar lavage fluid associated with clinical and radiological signs of pneumonia [17]; 2) primary thyrotoxicosis diagnosed during hospital stay [3]; 3) duration of follow-up $\geq 30$ days after hospital discharge. Exclusion criteria were: 1) treatment with levo-thyroxine or anti-thyroid drugs before and at the time of first thyrotropin (TSH) evaluation; 2) treatment with drugs interfering with thyroid function after recovery of COVID-19.

Page $2 / 9$ 
The diagnosis of clinical and subclinical thyrotoxicosis was based on suppressed serum TSH values associated with high or normal serum free-thyroxine (FT4), respectively. Among 58 patients who developed a SARS-CoV2-related thyrotoxicosis [3], 23 patients (39.7\%) died, whereas 6 patients (10.3\%) were lost at follow-up. Therefore, 29 patients (11 females, 18 males; median age 64 years, range: 43-85) were enrolled in this prospective study. Nobody of these patients received corticosteroids during hospital stay.

The first end-point was the evaluation of serum TSH values after at least 30 days of follow-up. As secondary end-points, we also evaluated serum FT4 (24 cases), free-triiodiothyronine (FT3) (14 cases), TSH receptor antibodies (TRAb) (29 cases), thyroglobulin antibodies (TgAb) $(29$ cases) and thyroperoxidase antibodies (TPOAb) $(29$ cases) and ultrasonographic thyroid structure (29 cases) at the follow-up.

The study was approved by the Ethical Committee of IRCCS Humanitas Research Hospital, and the patients gave their consent to use the clinical and biochemical data for research purposes.

\section{Biochemical assays}

Serum TSH, FT4, FT3 were measured at 8.00 a.m. using chemiluminescent methods on the Beckman Coulter DxI 800 Access ${ }^{\circledR}$ immunoassay system. In our laboratory, the reference ranges of TSH, FT4 and FT3 were 0.34-4.80 mU/L, 7.82-17.29 pmol/L and 3.38-6.45 pmol/L, respectively. TRAb were determined using the TRACE (Time-Resoved Amplified Cryptate Emission) on the Kryptor analyzer and reference range in our laboratory was $<1.8 \mathrm{IU} / \mathrm{L}$. Overt thyrotoxicosis was defined by low TSH values and serum FT3 and/or FT4 above the reference ranges. Overt hypothyroidism was defined by high TSH values and serum FT4 and/or FT3 below the reference ranges. Subclinical thyroid dysfunction was defined when TSH was either low or high accompanied by FT4 and FT3 in the reference ranges.

\section{Ultrasound evaluation of thyroid gland}

Ultrasonographic examination of the thyroid was performed with a linear transducer 5-14 (CANON APLIO A). The echogenicity was evaluated by a standardized comparison of thyroid parenchyma with the adjacent sternohyoideus, sternothyroideus and sternocleidomastoideus muscles, in a longitudinal scan of the thyroid lobes. Thyroid volume was calculated measuring the three axes of the thyroid lobes; for all measurements, the transducer kept perpendicular the skin surface. The length was measured from the most cranial to the most caudal part of the lobe on a screen picture following the longitudinal axis of the lobe; the maximal width and depth of the lobe were measured horizontally on a screen picture cross-sectional to the longitudinal axis of the lobe, taken from the middle half of the lobe in the lateral plane. Thyroid volume was calculated for each lobe separately using the formula for a rotation ellipsoid (length $\mathrm{x}$ width $\mathrm{x}$ depth $\mathrm{x} \pi / 6$ ) [18].

\section{Statistical analyses}

Data were presented as median and range, unless otherwise stated. The un-paired comparisons were performed by Mann-Whitney's and Kruskal-Wallis' tests, whereas paired data were compared by Wilcoxon's and Friedman's tests. Frequencies were compared by the Chi-Square's test, with Fisher correction when appropriate. A p value $<0.05$ was considered as significant.

\section{Results}

Table 1 reports the individual data of 29 subjects with SARS-CoV2-related thyrotoxicosis who were included in the prospective evaluation of thyroid function and structure. As compared to patients with SARS-CoV2-related thyrotoxicosis who died during hospital stay, the enrolled subjects were significantly younger (64 years, range: $43-85$ vs. 79 years, range: $67-90 ; P<0.001$ ) and had higher serum FT3 values (4.50 pmol/L, range: 3.28-7.33 vs. $4.05 \mathrm{pmol} / \mathrm{L}$, range: $3.00-5.06 ; P=0.016)$, without significant differences in sex $(P=0.608)$, serum FT4 $(P=0.934)$ and TSH $(P=0.233)$ values.

At the study entry, overt and subclinical thyrotoxicosis were found in 17 patients (58.62\%) and 12 (41.38\%) patients, respectively (Table 1). After a median period of 90 days (range 30-120), median serum TSH values increased (29 cases; from $0.21 \mathrm{mU} / \mathrm{L}$, range: 0.02-0.33 to $1.49 \mathrm{mU} / \mathrm{L}$, range: $0.55-6.78 ; P<0.001$; Figure 1 ) and FT4 values decreased (24 cases from $18.59 \mathrm{pmol} / \mathrm{L}$, range: $12.00-$ 27.66 to $13.00 \mathrm{pmol} / \mathrm{L}$, range: 4.11-17.00; $P=0.001$ ), without significant change in serum FT3 (14 cases; $P=0.572$ ). At the follow-up, 
serum TSH values were below $1.0 \mathrm{mU} / \mathrm{L}$ in 11 cases (37.9\%), between 1.0 and $3.0 \mathrm{mU} / \mathrm{L}$ in 14 cases (48.3\%) and above $3.0 \mathrm{mU} / \mathrm{L}$ in 3 cases (13.8\%) (Figure 1). At the follow-up, 28 subjects (96.6\%) became euthyroid whereas overt hypothyroidism developed in one case (TSH $6.78 \mathrm{mU} / \mathrm{L}$, FT4 $4.11 \mathrm{pmol} / \mathrm{L}$, FT3 $1.8 \mathrm{pmol} / \mathrm{L}$ ) (Figure 1).

At the follow-up, all subjects resulted to be negative for TgAb, TPOAb and TRAb. At the ultrasound evaluation of thyroid gland, hypoecogenicity was found in 10 patients (34.5\%) (Table 1 and Figure 2) with a prevalence significantly higher in cases with serum $\mathrm{TSH}>3.0 \mathrm{mU} / \mathrm{l}$ as compared to those with TSH values below $1.0 \mathrm{mU} / \mathrm{L}(75.0 \% \mathrm{vs} .9 .1 \% ; P=0.039)$. Thyroid volume resulted to be increased or decreased in 4 (13.8\%) and $3(10.3 \%)$ patients, respectively (Table 1), without any association with serum TSH values at the follow-up (Table 1).

\section{Discussion}

In this prospective study, all but one subjects with SARS-CoV-2-related thyrotoxicosis became euthyroid after recovery of COVID-19. However, ultrasound evaluation of thyroid structure revealed hypoecogenicity in one-third of patients in relationship with higher serum TSH values at follow-up.

Since the first months of COVID-19 outbreak, thyroid dysfunction has been reported in a remarkable number of subjects with SARSCoV-2 infection. Specifically, thyrotoxicosis resembling SAT was consistently described in hospitalized patients with COVID-19 $[3,4,9,10,8,6,7,11]$. Thyroid cells might be potential target for SARS-CoV-2 entry as they have been found to express ACE-2 mRNA (13) and thyroid follicular and parafollicular epithelium might be directly damaged by the virus [12] with consequent alteration of thyroid structure and function. The clinical relevance of thyroid dysfunction in the setting of COVID-19 is still uncertain. In our previous report [3], overt thyrotoxicosis was associated with alterations of atrial fibrillation and thromboembolic events. More recently, thyroid dysfunction was shown to negatively influence outcome of COVID-19, in terms of higher risk of acute respiratory distress, cardiac injury, fatal events and duration of hospitalization [19]. In our cohort, about 40\% of patients with SARS-CoV2related thyrotoxicosis died during hospital stay and noteworthy these subjects showed significantly lower serum FT3 values as compared to the survivors. This finding is consistent with the concept that a more severe acute disease induced adaptation of the hypotalamic-pituitary-thyroid axis [14], leading to develop a "low T3 syndrome" associated with SARS-CoV-2-related thyrotoxicosis.

In longitudinal studies, persistent hypothyroidism was found to develop in up to 15-20 \% of subjects with SAT [20-23], in relationship with persistent alterations of thyroid structure [20,23]. The outcome of SARS-CoV2-related thyrotoxicosis is unclear $[3,4,14]$ and data on thyroid echographic parameters in this setting are scanty [3,4]. In our prospective study, the majority of subjects $(96 \%)$ achieved euthyroidism in few weeks after recovery of COVID-19, while only one subject became hypothyroidism. Such a low prevalence of overt hypothyroidism could be possibly related to a mild parenchymal damage induced by SARS-CoV-2 as compared to the typical SAT. However, a relevant number of subjects had serum TSH in the highest part of reference range in close relationship with hypoecogenicity of parenchyma at ultrasound evaluation of thyroid gland. All patients were found negative for thyroid autoantibodies suggesting that SARS-CoV-2 infection may have not induced an autoimmune process against thyroid gland [24]. On the other hand, thyroid gland hypoecogenicity may truly reflect persistent alterations of thyroid parenchyma induced by the recent SARS-CoV-2 infection [25], possibly predisposing the subjects to develop late-onset hypothyroidism [20,23].

This study has limitations. The short-term follow-up and the small size of study group restricted to only survivors with subclinical or overt thyrotoxicosis, likely did not allow to capture all cases developing thyroid dysfunction after SARS-CoV-2 infection [20].

However, the finding of hypoecogenicity in a remarkable number of subjects with recent SARS-CoV-2-related thyrotoxicosis provided a rationale for planning a strict follow-up in these cases in order to identify possible late-onset thyroid dysfunction

In conclusion, this prospective and monocentric study shows that most of subjects with SARS-CoV-2-related thyrotoxicosis normalize thyroid function few weeks after resolution of COVID-19. However, thyroid hypoecogenicity was found in a remarkable number of them and future longer-term studies will clarify whether this ultrasonographic alteration may predispose to develop lateonset thyroid dysfunction.

\section{Declarations}

Funding: This research did not receive any specific grant from any funding agency in the public, commercial or not-for-profit sector. 
Conflicts of interest/Competing interests: The authors declare that there is no conflict of interest that could be perceived as prejudicing the impartiality of the research reported.

Availability of data and material: Data are stored in the Institutional repository Zenodo.

Ethics approvalConsent to participate: The study was approved by the Ethical Committee of IRCCS Humanitas Research Hospital, and the patients gave their consent to use the clinical and biochemical data for research purposes.

\section{References}

1. Huang, C., Wang, Y., Li, X., Ren, L., Zhao, J., Hu, Y., Zhang, L., Fan, G., Xu, J., Gu, X., Cheng, Z., Yu, T., Xia, J., Wei, Y., Wu, W., Xie, X., Yin, W., Li, H., Liu, M., Xiao, Y., Gao, H., Guo, L., Xie, J., Wang, G., Jiang, R., Gao, Z., Jin, Q., Wang, J., Cao, B.: Clinical features of patients infected with 2019 novel coronavirus in Wuhan, China. Lancet (London, England) 395(10223), 497-506 (2020). doi:10.1016/s0140-6736(20)30183-5

2. Johnson, K.D., Harris, C., Cain, J.K., Hummer, C., Goyal, H., Perisetti, A.: Pulmonary and Extra-Pulmonary Clinical Manifestations of COVID-19. Frontiers in medicine 7, 526 (2020). doi:10.3389/fmed.2020.00526

3. Lania, A., Sandri, M.T., Cellini, M., Mirani, M., Lavezzi, E., Mazziotti, G.: Thyrotoxicosis in patients with COVID-19: the THYRCOV study. European journal of endocrinology 183(4), 381-387 (2020). doi:10.1530/eje-20-0335

4. Muller, I., Cannavaro, D., Dazzi, D., Covelli, D., Mantovani, G., Muscatello, A., Ferrante, E., Orsi, E., Resi, V., Longari, V., Cuzzocrea, M., Bandera, A., Lazzaroni, E., Dolci, A., Ceriotti, F., Re, T.E., Gori, A., Arosio, M., Salvi, M.: SARS-CoV-2-related atypical thyroiditis. The lancet. Diabetes \& endocrinology 8(9), 739-741 (2020). doi:10.1016/s2213-8587(20)30266-7

5. Lui, D.T.W., Lee, C.H., Chow, W.S., Lee, A.C.H., Tam, A.R., Fong, C.H.Y., Law, C.Y., Leung, E.K.H., To, K.K.W., Tan, K.C.B., Woo, Y.C., Lam, C.W., Hung, I.F.N., Lam, K.S.L.: Thyroid Dysfunction in Relation to Immune Profile, Disease Status and Outcome in 191 Patients with COVID-19. The Journal of clinical endocrinology and metabolism (2020). doi:10.1210/clinem/dgaa813

6. Ippolito, S., Dentali, F., Tanda, M.L.: SARS-CoV-2: a potential trigger for subacute thyroiditis? Insights from a case report. Journal of endocrinological investigation 43(8), 1171-1172 (2020). doi:10.1007/s40618-020-01312-7

7. Mattar, S.A.M., Koh, S.J.Q., Rama Chandran, S., Cherng, B.P.Z.: Subacute thyroiditis associated with COVID-19. BMJ Case Rep 13(8) (2020). doi:10.1136/bcr-2020-237336

8. Ruggeri, R.M., Campennì, A., Siracusa, M., Frazzetto, G., Gullo, D.: Subacute thyroiditis in a patient infected with SARS-COV-2: an endocrine complication linked to the COVID-19 pandemic. Hormones (Athens), 1-3 (2020). doi:10.1007/s42000-020-00230-w

9. Brancatella, A., Ricci, D., Cappellani, D., Viola, N., Sgrò, D., Santini, F., Latrofa, F.: Is Subacute Thyroiditis an Underestimated Manifestation of SARS-CoV-2 Infection? Insights From a Case Series. J Clin Endocrinol Metab 105(10) (2020). doi:10.1210/clinem/dgaa537

10. Campos-Barrera, E., Alvarez-Cisneros, T., Davalos-Fuentes, M.: Subacute Thyroiditis Associated with COVID-19. Case reports in endocrinology 2020, 8891539 (2020). doi:10.1155/2020/8891539

11. Chakraborty, U., Ghosh, S., Chandra, A., Ray, A.K.: Subacute thyroiditis as a presenting manifestation of COVID-19: a report of an exceedingly rare clinical entity. BMJ case reports 13(12) (2020). doi:10.1136/bcr-2020-239953

12. Wei, L., Sun, S., Xu, C.H., Zhang, J., Xu, Y., Zhu, H., Peh, S.C., Korteweg, C., McNutt, M.A., Gu, J.: Pathology of the thyroid in severe acute respiratory syndrome. Hum Pathol 38(1), 95-102 (2007). doi:10.1016/j.humpath.2006.06.011

13. Rotondi, M., Coperchini, F., Ricci, G., Denegri, M., Croce, L., Ngnitejeu, S.T., Villani, L., Magri, F., Latrofa, F., Chiovato, L.: Detection of SARS-COV-2 receptor ACE-2 mRNA in thyroid cells: a clue for COVID-19-related subacute thyroiditis. Journal of endocrinological investigation, 1-6 (2020). doi:10.1007/s40618-020-01436-w

14. Khoo, B., Tan, T., Clarke, S.A., Mills, E.G., Patel, B., Modi, M., Phylactou, M., Eng, P.C., Thurston, L., Alexander, E.C., Meeran, K., Comninos, A.N., Abbara, A., Dhillo, W.S.: Thyroid function before, during and after COVID-19. J Clin Endocrinol Metab (2020). doi:10.1210/clinem/dgaa830

15. Chen, M., Zhou, W., Xu, W.: Thyroid Function Analysis in 50 Patients with COVID-19: A Retrospective Study. Thyroid : official journal of the American Thyroid Association (2020). doi:10.1089/thy.2020.0363 
16. Leung, T.Y.M., Chan, A.Y.L., Chan, E.W., Chan, V.K.Y., Chui, C.S.L., Cowling, B.J., Gao, L., Ge, M.Q., Hung, I.F.N., Ip, M.S.M., Ip, P., Lau, K.K., Lau, C.S., Lau, L.K.W., Leung, W.K., Li, X., Luo, H., Man, K.K.C., Ng, V.W.S., Siu, C.W., Wan, E.Y.F., Wing, Y.K., Wong, C.S.M., Wong, K.H.T., Wong, I.C.K.: Short- and potential long-term adverse health outcomes of COVID-19: a rapid review. Emerging microbes \& infections 9(1), 2190-2199 (2020). doi:10.1080/22221751.2020.1825914

17. Guan, W.J., Ni, Z.Y., Hu, Y., Liang, W.H., Ou, C.Q., He, J.X., Liu, L., Shan, H., Lei, C.L., Hui, D.S.C., Du, B., Li, L.J., Zeng, G., Yuen, K.Y., Chen, R.C., Tang, C.L., Wang, T., Chen, P.Y., Xiang, J., Li, S.Y., Wang, J.L., Liang, Z.J., Peng, Y.X., Wei, L., Liu, Y., Hu, Y.H., Peng, P., Wang, J.M., Liu, J.Y., Chen, Z., Li, G., Zheng, Z.J., Qiu, S.Q., Luo, J., Ye, C.J., Zhu, S.Y., Zhong, N.S.: Clinical Characteristics of Coronavirus Disease 2019 in China. The New England journal of medicine 382(18), 1708-1720 (2020). doi:10.1056/NEJMoa2002032

18. Knudsen, N., Bols, B., Bülow, I., Jørgensen, T., Perrild, H., Ovesen, L., Laurberg, P.: Validation of ultrasonography of the thyroid gland for epidemiological purposes. Thyroid 9(11), 1069-1074 (1999). doi:10.1089/thy.1999.9.1069

19. Zhang, Y., Lin, F., Tu, W., Zhang, J., Choudhry, A.A., Ahmed, O., Cheng, J., Cui, Y., Liu, B., Dai, M., Chen, L., Han, D., Fan, Y., Zeng, Y., Li, W., Li, S., Chen, X., Shen, M., Pan, P.: Thyroid dysfunction may be associated with poor outcomes in patients with COVID-19. Molecular and cellular endocrinology 521, 111097 (2021). doi:10.1016/j.mce.2020.111097

20. Zhao, N., Wang, S., Cui, X.J., Huang, M.S., Wang, S.W., Li, Y.G., Zhao, L., Wan, W.N., Li, Y.S., Shan, Z.Y., Teng, W.P.: Two-Years Prospective Follow-Up Study of Subacute Thyroiditis. Frontiers in endocrinology 11, 47 (2020). doi:10.3389/fendo.2020.00047

21. Bogazzi, F., Dell'Unto, E., Tanda, M.L., Tomisti, L., Cosci, C., Aghini-Lombardi, F., Sardella, C., Pinchera, A., Bartalena, L., Martino, E.: Long-term outcome of thyroid function after amiodarone-induced thyrotoxicosis, as compared to subacute thyroiditis. Journal of endocrinological investigation 29(8), 694-699 (2006). doi:10.1007/bf03344178

22. Alfadda, A.A., Sallam, R.M., Elawad, G.E., Aldhukair, H., Alyahya, M.M.: Subacute thyroiditis: clinical presentation and long term outcome. International journal of endocrinology 2014, 794943 (2014). doi:10.1155/2014/794943

23. Nishihara, E., Amino, N., Ohye, H., Ota, H., Ito, M., Kubota, S., Fukata, S., Miyauchi, A.: Extent of hypoechogenic area in the thyroid is related with thyroid dysfunction after subacute thyroiditis. Journal of endocrinological investigation 32(1), 33-36 (2009). doi:10.1007/bf03345675

24. Cuan-Baltazar, Y., Soto-Vega, E.: Microorganisms associated to thyroid autoimmunity. Autoimmunity reviews 19(9), 102614 (2020). doi:10.1016/j.autrev.2020.102614

25. Omori, N., Omori, K., Takano, K.: Association of the ultrasonographic findings of subacute thyroiditis with thyroid pain and laboratory findings. Endocrine journal 55(3), 583-588 (2008). doi:10.1507/endocrj.k07e-163

\section{Tables}

Table 1: Individual clinical data of patients with SARS-CoV-2-related thyrotoxicosis prospectively evaluated after recovery of COVID19. 


\begin{tabular}{|c|c|c|c|c|c|c|c|c|c|c|}
\hline \multirow[b]{2}{*}{ Sex } & \multicolumn{4}{|c|}{ BASELINE } & \multicolumn{6}{|c|}{ FOLLOW-UP } \\
\hline & $\begin{array}{l}\text { Age } \\
\text { (years) }\end{array}$ & $\begin{array}{l}\text { TSH } \\
(\mathrm{mU} / \mathrm{L})\end{array}$ & $\begin{array}{l}\text { FT4 } \\
(\mathrm{pmol} / \mathrm{L})\end{array}$ & $\begin{array}{l}\text { FT3 } \\
\text { (pmol/L) }\end{array}$ & $\begin{array}{l}\text { Duration } \\
\text { (days) }\end{array}$ & $\begin{array}{l}\text { TSH } \\
(\mathrm{mU} / \mathrm{L})\end{array}$ & $\begin{array}{l}\text { FT4 } \\
\text { (pmol/L) }\end{array}$ & $\begin{array}{l}\text { FT3 } \\
\text { (pmol/L) }\end{array}$ & $\begin{array}{l}\text { Thyroid } \\
\text { volume }\end{array}$ & $\begin{array}{l}\text { Thyroid } \\
\text { hypoecogenicity }\end{array}$ \\
\hline$M$ & 66 & 0.33 & 14.36 & 4.78 & 30 & 1.90 & 15.00 & $N A$ & $\mathrm{~N}$ & NO \\
\hline $\mathrm{F}$ & 58 & 0.31 & 19.00 & 3.70 & 41 & 2.25 & 13.00 & 4.90 & $\mathrm{~N}$ & NO \\
\hline $\mathrm{F}$ & 85 & 0.20 & 19.00 & 7.33 & 43 & 0.70 & 10.48 & 6.00 & $\mathrm{~N}$ & NO \\
\hline $\mathrm{F}$ & 55 & 0.21 & 17.48 & 4.95 & 44 & 0.55 & 13.97 & 5.73 & $\mathrm{~N}$ & NO \\
\hline $\mathrm{F}$ & 64 & 0.30 & 22.23 & 5.28 & 60 & 3.19 & 12.50 & 3.00 & $\mathrm{~N}$ & YES \\
\hline M & 43 & 0.32 & 12.53 & 4.77 & 60 & 1.81 & 11.00 & $N A$ & $\mathrm{~N}$ & NO \\
\hline M & 61 & 0.17 & 19.93 & 5.05 & 60 & 1.31 & 14.00 & $N A$ & $\mathrm{~N}$ & YES \\
\hline M & 53 & 0.12 & 16.86 & 3.86 & 60 & 0.57 & 13.00 & $N A$ & $\mathrm{~N}$ & YES \\
\hline M & 61 & 0.29 & 12.00 & 4.00 & 62 & 1.11 & 9.93 & 5.16 & $\mathrm{D}$ & YES \\
\hline $\mathrm{F}$ & 60 & 0.32 & 18.50 & 4.82 & 66 & 0.70 & 16.00 & NA & $\mathrm{N}$ & NO \\
\hline M & 48 & 0.24 & 15.68 & 4.92 & 70 & 0.45 & 11.00 & NA & $N$ & NO \\
\hline$M$ & 49 & 0.12 & 13.65 & 4.34 & 90 & 6.78 & 4.11 & 1.80 & $\mathrm{~N}$ & YES \\
\hline$M$ & 81 & 0.19 & 27.66 & 3.49 & 90 & 3.77 & 12.60 & $N A$ & I & YES \\
\hline $\mathrm{F}$ & 73 & 0.13 & 22.44 & 4.09 & 90 & 1.84 & 12.23 & 2.68 & $N$ & NO \\
\hline$M$ & 76 & 0.20 & 15.56 & 4.53 & 90 & 1.64 & 12.87 & 4.73 & $\mathrm{~N}$ & YES \\
\hline $\mathrm{F}$ & 64 & 0.33 & 20.75 & 4.10 & 90 & 1.60 & 14.30 & 5.00 & $D$ & NO \\
\hline$M$ & 74 & 0.33 & 16.38 & 5.20 & 90 & 1.36 & 10.62 & 6.58 & I & NO \\
\hline $\mathrm{F}$ & 80 & 0.14 & 13.59 & 3.86 & 90 & 1.21 & 15.10 & 5.00 & $\mathrm{~N}$ & YES \\
\hline $\mathrm{F}$ & 67 & 0.29 & 22.40 & 4.50 & 90 & 0.92 & 17.00 & $N A$ & $\mathrm{~N}$ & NO \\
\hline $\mathrm{F}$ & 74 & 0.30 & 18.68 & 4.50 & 90 & 0.86 & 15.00 & 4.30 & D & NO \\
\hline$M$ & 77 & 0.33 & 15.82 & 3.28 & 90 & 0.66 & 13.00 & $N A$ & $\mathrm{~N}$ & NO \\
\hline$M$ & 62 & 0.30 & 16.60 & 4.69 & 92 & 2.11 & $N A$ & $N A$ & I & YES \\
\hline$M$ & 57 & 0.14 & 24.05 & 4.00 & 93 & 1.50 & 12.28 & 4.04 & $\mathrm{~N}$ & YES \\
\hline$M$ & 70 & 0.05 & 30.49 & 3.50 & 96 & 3.44 & $N A$ & $N A$ & I & NO \\
\hline$M$ & 68 & 0.08 & 18.26 & 4.74 & 96 & 0.93 & $N A$ & $N A$ & $\mathrm{~N}$ & NO \\
\hline $\mathrm{F}$ & 77 & 0.12 & 26.30 & 4.30 & 97 & 1.49 & 13.66 & 2.77 & $\mathrm{~N}$ & NO \\
\hline$M$ & 57 & 0.20 & 16.90 & 4.50 & 100 & 0.63 & $N A$ & $N A$ & $\mathrm{~N}$ & NO \\
\hline$M$ & 65 & 0.09 & 17.59 & 4.75 & 120 & 1.03 & $N A$ & $N A$ & $\mathrm{~N}$ & NO \\
\hline$M$ & 63 & 0.33 & 19.00 & 5.00 & 120 & 0.93 & 16.00 & $N A$ & $\mathrm{~N}$ & NO \\
\hline
\end{tabular}

F, females; FT3, free-iodiothyronine; FT4, free-thyroxine; I, increased; M, males; N, normal; NA, not available; TSH, thyrotropin.

Figures 


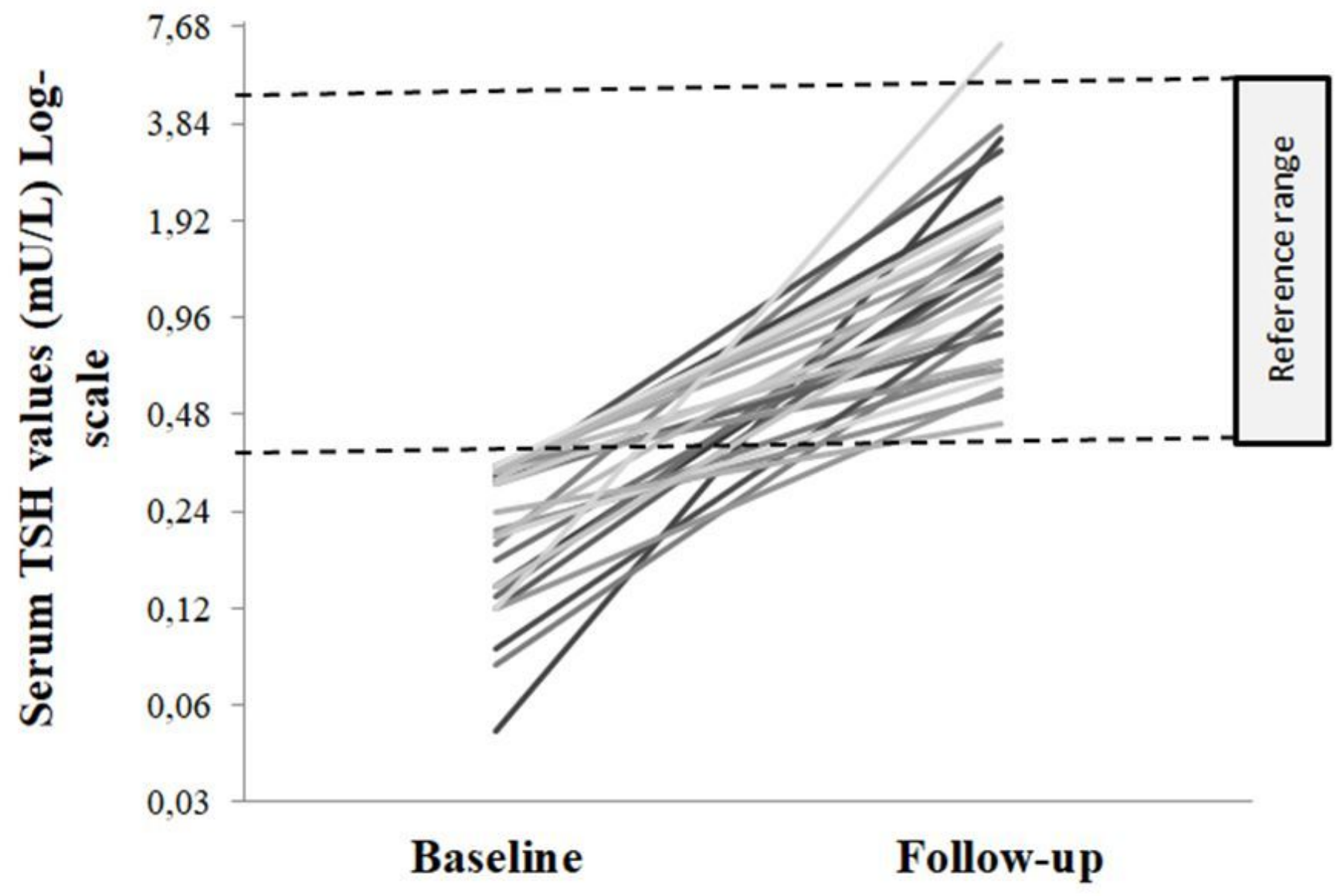

Figure 1

Individual outcome of serum thyrotropin (TSH) values, expressed in logarithmic scale, in 29 subjects with SARS-CoV2-related thyrotoxicosis followed up for a median period of 90 days (range 30-120). 


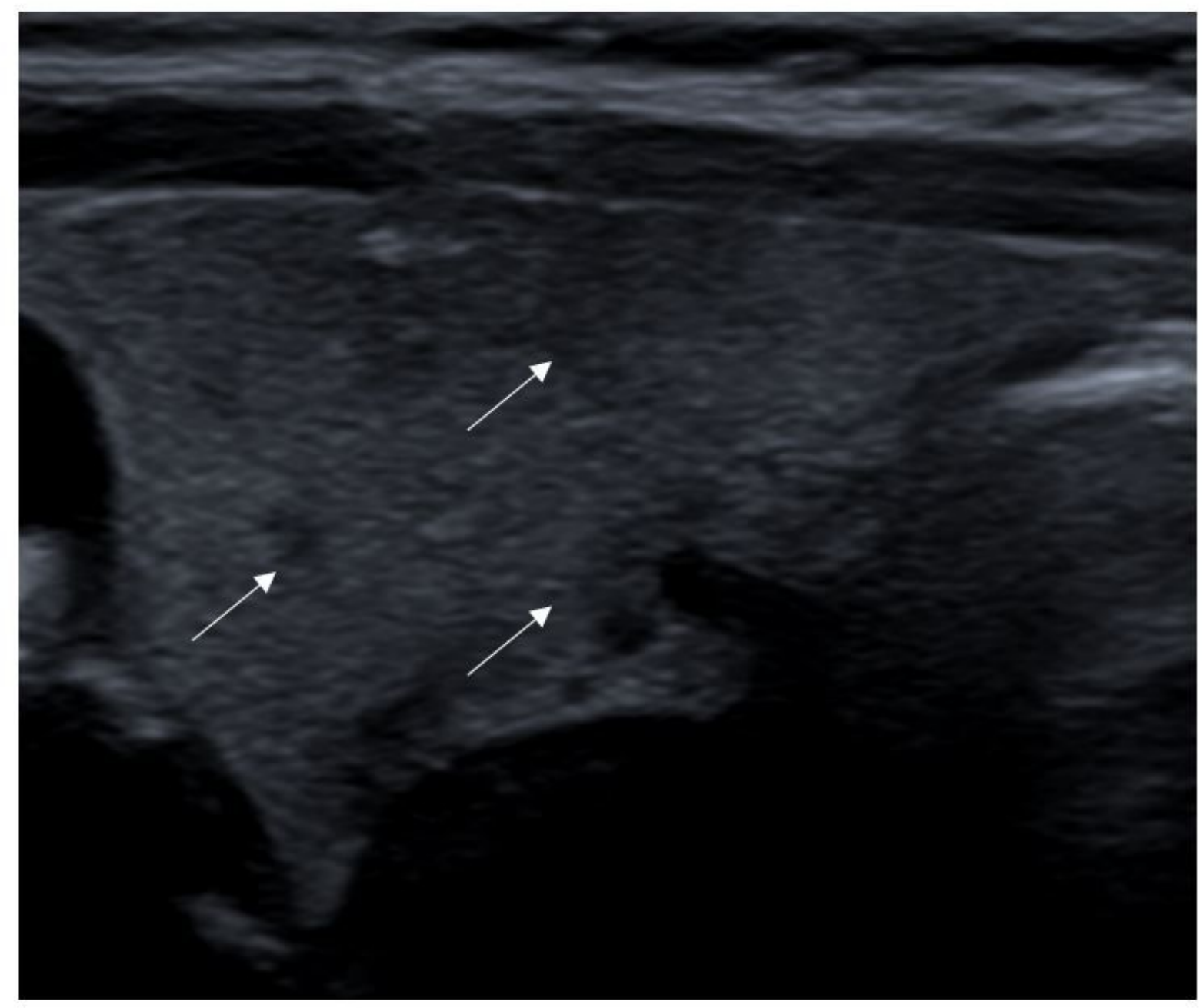

Figure 2

Thyroid hypoecogenicity in a patient with recent SARS-CoV-2-related thyrotoxicosis. 